\title{
ANALISIS EKONOMI DAN KRITERIA CODE OF CONDUCT FOR RESPONSIBLE FISHERIES ALAT TANGKAP BAGAN PERAHU DI PPI AIR BANGIS SUMATERA BARAT
}

\section{Economic Analysis And Criteria Code Of Conduct For Responsible Fisheries Boat Chart In Ppi Air Bangis-West Sumatera}

\author{
Muhammad Nur Arkham ${ }^{*}$, Windri Gunawan², Ratih Purnama Sari², Mathius \\ Tiku $^{2}$, Rangga Bayu Kusuma Haris ${ }^{2}$, Roma Yuli F. Hutapea ${ }^{2}$ \\ ${ }^{1}$ Perkumpulan Peneliti Sistem Sosial Ekologi Perikanan dan Kelautan, Bogor, Indonesia \\ ${ }^{2}$ Politeknik Kelautan dan Perikanan Dumai - BRSDMKP, Dumai, Indonesia
}

*Corresponding author: arkham.mnur@gmail.com

\begin{abstract}
ABSTRAK
Nagari Air Bangis merupakan sebuah desa yang berada di Provinsi Sumatera Barat. Potensi sumberdaya perikanan yang ada di Air Bangis sangat besar dan banyak yang memiliki usaha perikanan tangkap. Salah satu usaha perikanan tangkap yang terus berkembang adalah alat tangkap bagan perahu. Tujuan dari penelitian ini adalah untuk mengetahui nilai ekonomi dan menggambarkan dukungan pengembangan alat tangkap bagan perahu berdasarkan CCRF di Perairan Air Bangis, Provinsi Sumatera Barat. Metode pengumpulan data yaitu dengan survey dan observasi secara langsung, sedangkan untuk teknik pemilihan responden menggunakan metode purposive samplaing. Analisis data yang digunakan adalah analisis ekonomi dan kriteria alat tangkap ramah lingkungan berdasarkan code of conduct for responsible fisheries (CCRF). Hasil penelitian menyebutkan bahwa alat tangkap bagan perahu yang dioperasikan oleh nelayan di PPI Air Bangis secara ekonomi menguntungkan dan layak untuk dilanjutkan usahanya dilihat dari nilai $\mathrm{R} / \mathrm{C}$ rasio sebesar 1,35 dengan keuntungan per tahun sebesar Rp. 442.500.000,00. Dilihat dari segi lingkungan juga menunjukkan bahwa alat tangkap bagan perahu termasuk dalam kategori sangat ramah lingkungan dari hasil penilaian kriteria dengan pendekatan CCRF menunjukkan bobot ratarata sebesar 31,4 .
\end{abstract}

Kata kunci: code of conduct for responsible fisheries, kelayakan ekonomi, nelayan kecil, bagan perahu, PPI Air Bangis

\begin{abstract}
Nagari Air Bangis is a village located in West Sumatra Province. The potential of fisheries resources in Air Bangis is very large and many have capture fisheries businesses. One of the capture fisheries businesses that continues to grow is the boat chart fishing gear. The purpose of this study was to determine the economic value and describe the support for the development of boat chart fishing gear based on CCRF in Air Bangis Waters, West Sumatra Province. The data collection method is by survey and direct observation, while for the respondent selection technique using the purposive sampling method. The data analysis used is an economic analysis and criteria for environmentally friendly fishing gear based on the code of conduct for responsible fisheries (CCRF). The results of the study stated that the boat chart fishing gear operated by fishermen at PPI Air Bangis was economically profitable and feasible to continue their business as seen from the $R / C$ ratio of 1.35 with an annual profit of Rp. 442,500,000.00. From an environmental perspective, it also shows that
\end{abstract}


the boat chart fishing gear is included in the very environmentally friendly category. The results of the criteria assessment using the CCRF approach show an average weight of 31.4.

Keywords: economic feasibility, code of conduct for responsible fisheries, small fisherman, boat chart, PPI Air Bangis

\section{PENDAHULUAN}

Provinsi Sumatera Barat yang berada di bagian Barat Sumatera memiliki sumberdaya pesisir dan laut yang potensial, dimana luas lautnya berhubungan langsung dengan Samudera Hindia sebesar $186.580 \mathrm{Km}^{2}$ (termasuk ZEE), dengan panjang garis pantai 2.045 $\mathrm{km}$ dan mempunyai 19 kabupaten/kota, tujuh diantaranya mempunyai wilayah pesisir salah satunya kabupaten Pasaman Barat, Nagari Air Bangis Kecamatan Sungai Beremas. Hasil kajian terhadap stok dan potensi sumber daya perikanan Sumatera Barat adalah sebesar 340.712 ton/tahun (Suman et al., 2014) dan Provinsi Sumatera Barat termasuk provinsi yang mampu mengelola potensi perikanan di daerahnya.

Nagari Air Bangis merupakan Desa yang berada di Kecamatan Sungai Beremas terletak pada $00^{\circ} 09^{\prime \prime}-00^{\circ} 21^{\prime \prime} \mathrm{LU}$ dan 99 10" - 99 $34 "$ BT dengan luas wilayah $440.48 \mathrm{Km}^{2}$ (BPS Air Bangis, 2019) yang merupakan salah satu nagari yang memiliki usaha perikanan tangkap yang relatif besar dibandingkan dengan nagari-nagari lainnya di pantai Barat Pasaman Barat. Pengusaha perikanan yang ada di Nagari Air Bangis telah berperan aktif dalam memajukan produksi perikanan lokal. Peran aktif yang ditunjukkan terlihat dari jumlah dan ukuran armada serta alat tangkap yang dioperasikan relatif lebih besar sehingga menghasilkan produksi yang lebih besar pula. Pengusaha perikanan tangkap yang ada di Nagari Air Bangis pada umumnya $60 \%$ menggunakan alat tangkap bagan perahu (lift net) dan $40 \%$ alat tangkap lainnya seperti purse seine, gillnet, bubu dan lain-lain (Setiawan et al., 2015).

Alat penangkapan ikan (API) modern sudah mulai menyerap banyak tenaga kerja, hal ini dikarenakan API tersebut memiliki produktivitas yang tinggi. Salah satu alat penangkapan ikan di Nagari Air Bangis yang mulai berkembang adalah Bagan Perahu (Lift Net). Alat penangkapan ikan ini terus berkembang dan beradaptasi dengan nelayan kecil yang ada di Pesisir Pantai Pasaman Barat. Armada penangkapan ikan yang digunakan untuk mengoperasikan alat tangkap lift net ini rata-rata memiliki ukuran diatas $30 \mathrm{GT}$ dengan operasi penangkapan sebanyak 7 trip/bulan (Putra et al., 2020). Keberadaan alat tangkap ini telah memberikan kontribusi bagi peningkatan produksi perikanan dan penyerapan tenaga kerja di Nagari Air Bangis. Oleh karena itu, usaha perikanan bagan perahu (lift net) ini memiliki potensi untuk terus dikembangkan secara berkelanjutan dan berbasis kearifan lokal.

Pemanfaatan sumberdaya perikanan secara bertanggung jawab dan berkelanjutan dapat mengurangi tekanan terhadap sumberdaya perikanan. Keberlanjutan sumberdaya perikanan dapat dipengaruhi oleh jenis alat tangkap yang. Sehingga diperlukan penelitian terkait dengan anilsis ekonomi dan kriteria alat tangkap bagan perahu (lift net) yang digunakan oleh nelayan kecil di Nagari Air Bangis berdasarkan code of conduct for responsible fisheries (CCRF). Tujuan dari penelitian ini adalah untuk mengetahui nilai ekonomi dan menggambarkan dukungan pengembangan alat tangkap bagan perahu (lift net) berdasarkan CCRF di Perairan Air Bangis, Provinsi Sumatera Barat.

\section{MATERI DAN METODE}

Penelitian dilakukan di Pangkalan Pendaratan Ikan (PPI) Air Bangis, 
Kecamatan Sungai Beremas, Kabupaten Pasaman Barat, Provinsi Sumatera Barat. Pemilihan Pengambilan data dilakukan pada tanggal 16 November-16 Desember 2020. Metode pengumpulan data yaitu dengan survey dan observasi secara langsung dengan ikut nelayan melakukan operasi penangkapan. Pengambilan data dilakukan selama 1 bulan operasi penangkapan ikan. Teknik pemilihan responden menggunakan metode purposive samplaing (Sugiyono, 2012) dengan tujuan untuk mengetahui analisis ekonomi dan gambaran dari dukungan alat tangkap began perahu terhadap aspekaspek didalam code of conduct for responsible fisheries (CCRF).

Data yang diperlukan dalam penelitian adalah data primer dan sekunder. Pengambulan data primer dilakukan dengan pendekatan wawancara mendalam dan pengisian kuesioner terhada nelayan began perahu dan ikut operasi penangkapannya. Data sekunder diperoleh dengan menelusuri literatur baik dari hasil penelitian yang dipublikasikan, data dari instansi pemerintah, prosiding, maupun bentuk publikasi lainnya dari beberapa pergurun tinggi.
Analisis ekonomi yang digunakan dalam penelitian ini terdapat 2 tahapan, yang pertama adalah dengan melihat struktur biaya usaha began perahu di PPI Air Bangis dengan metode full coasting (Mardianto et al., 2015) dengan melihat rincian biaya yang dikeluarkan dalam usaha penangkapan ikan. Terdapat 2 (dua) jenis biaya yang dianalisis pada struktur biaya yaitu biaya tidak tetap dan biaya tetap. Tahapan yang kedua yaitu melakukan analisis kelayakan jangka pendek dengan melihat total penerimaan, keuntungan dan tingkat keuntungan ( $\mathrm{R} / \mathrm{C}$ Ratio) (Arkham et al., 2020).

Analisis kriteria alat tangkap bagan perahu berdasarkan dukungan aspek CCRF ini dilakukan dengan mengajukan pertanyaan dalam wawancara mencakup kriteria tingkat ramah lingkungan (9 kriteria) dengan beberapa sub kriteria dan nilai skoringnya. Berikut ini adalah kriteria penangkapan ramah lingkungan menurut Code of Conduct for Responsible Fisheries dari FAO (1995) dalam Salim et al., (2019) yang disajikan pada Tabel 1.

Tabel 1. Kriteria alat tangkap ramah lingkungan berdasarkan CCRF 1995

\begin{tabular}{lllc}
\hline No & Kriteria & Sub Kriteria & Skor \\
$(1)$ & $(2)$ & $(3)$ & (4) \\
\hline
\end{tabular}

1. Selektivitas alat - Menangkap lebih dari 3 jenis ikan (ukuran berbeda 1 tangkap yang jauh)

tinggi - Menangkap 3 jenis ikan (ukuran berbeda jauh) 2

- Menangkap kurang dari 3 jenis ikan (ukuran kurang 3 lebih seragam)

- menangkap 1 jenis ikan (ukuran kurang lebih 4 seragam)

2. Tidak merusak - Menyebabkan rusaknya habitat (wilayah kerusakan habitat ekosistem pesisir dan laut luas)

- Menyebabkan rusaknya habitat (wilayah kerusakan sempit)

2




\begin{tabular}{|c|c|c|c|}
\hline (1) & (2) & (3) & (4) \\
\hline 3. & $\begin{array}{l}\text { Tidak } \\
\text { berbahaya } \\
\text { untuk nelayan }\end{array}$ & $\begin{array}{l}\text { - Dapat mengakibatkan kematian nelayan } \\
\text { - Dapat mengakibatkan cacat permanen pada nelayan } \\
\text { - Dapat mengakibatkan gangguan kesehatan (sifatnya } \\
\text { - sementara) } \\
\text { - Aman untuk nelayan }\end{array}$ & $\begin{array}{l}1 \\
2 \\
3\end{array}$ \\
\hline 4. & $\begin{array}{l}\text { Menghasilkan } \\
\text { ikan yang } \\
\text { berkualitas }\end{array}$ & $\begin{array}{l}\text { - Ikan kondisi mati dan busuk } \\
\text { - Ikan kondisi mati, segar dan cacat fisik } \\
\text { - Ikan kondisi mati dan segar } \\
\text { - } \text { Ikan dalam keadaan hidup }\end{array}$ & $\begin{array}{l}1 \\
2 \\
3 \\
4\end{array}$ \\
\hline 5. & $\begin{array}{l}\text { Hasil produksi } \\
\text { tidak } \\
\text { membahayakan } \\
\text { konsumen }\end{array}$ & 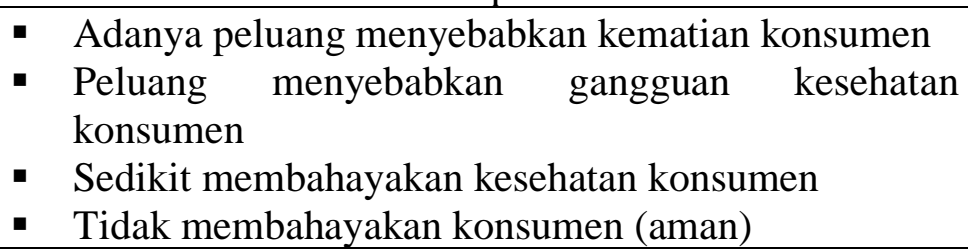 & $\begin{array}{l}1 \\
2\end{array}$ \\
\hline 6. & $\begin{array}{l}\text { Tangkapan } \\
\text { sampingan } \\
\text { (HTS) }\end{array}$ & $\begin{array}{l}\text { - HTS terdiri dari beberapa jenis dan tidak laku dijual } \\
\text { di pasar } \\
\text { - } \text { HTS terdiri dari beberapa jenis dan ada yang laku } \\
\text { dijual di pasar } \\
\text { - } \mathrm{HTS}<3 \text { jenis dan laku dijual di pasar } \\
\text { - } \mathrm{HTS}<3 \text { jenis dan mempunyai nilai jual tinggi di } \\
\text { pasar }\end{array}$ & $\begin{array}{l}3 \\
4\end{array}$ \\
\hline 7. & $\begin{array}{l}\text { Dampak } \\
\text { minimum } \\
\text { terhadap } \\
\text { biodiversitas }\end{array}$ & $\begin{array}{l}\text { - Dapat menyebabkan kematian semua organisme dan } \\
\text { habitat } \\
\text { - Dapat menyebabkan kematian beberapa jenis } \\
\text { (merusak habitat) } \\
\text { - Dapat menyebabkan kematian beberapa jenis (tidak } \\
\text { merusak habitat) } \\
\text { - aman bagi biodiversitas perairan }\end{array}$ & 2 \\
\hline 8. & $\begin{array}{l}\text { Tidak } \\
\text { menangkap } \\
\text { jenis biota yang } \\
\text { dilindungi/ } \\
\text { terancam punah }\end{array}$ & $\begin{array}{l}\text { - Biota dan ikan yang dilindungi sering tertangkap } \\
\text { - Biota dan ikan yang dilindungi tertangkap beberapa } \\
\text { kali } \\
\text { - Biota dan ikan yang dilindungi pernah tertangkap } \\
\text { - Biota dan ikan yang dilindungi tidak pernah } \\
\text { tertangkap }\end{array}$ & $\begin{array}{l}1 \\
2\end{array}$ \\
\hline 9. & $\begin{array}{l}\text { Dapat diterima } \\
\text { oleh nelayan/ } \\
\text { masyarakat }\end{array}$ & $\begin{array}{l}\text { - Biaya investasi relatif murah, } \\
\text { - Usaha yang menguntungkan } \\
\text { - Tidak bertentangan dengan budaya lokal } \\
\text { - Tidak melanggar peraturan yang ada }\end{array}$ & $\begin{array}{l}1 \\
2 \\
3 \\
4\end{array}$ \\
\hline
\end{tabular}

Hasil penilaian terhadap 9 kriteria berdasarkan sub kriteria pada Tabel 1 dijumlahkan secara total dari hasil hasil wawancara yang telah dilakukan. Jumlah total dari 9 kriteria tersebut nantinya digunakan untuk pengambilan keputusan sejauh mana alat tangkap bagan perahu tersebut layak untuk dikembangkan secara keramahan lingkungannya. Ketentuan dalam pengambilan keputusan tersebut mengacu pada penilaian CCRF-FAO (1995) dalam Salim et al., (2019) dengan batasan nilai sebagai berikut:
Nilai 1-9 : sangat tidak ramah lingkungan
Nilai 10-18 : tidak ramah lingkungan
Nilai 19-27 : ramah lingkungan
Nilai 28-36 : sangat ramah lingkungan 


\section{HASIL DAN PEMBAHASAN}

\section{Analisis Ekonomi}

Biaya Investasi

Investasi merupakam modal awal yang diperlukan untuk kegiatan operasional suatu usaha. Investasi yang digunakan dalam usaha perikanan tangkap began perahun (liftnet) sebesar Rp. 1.071.550.000,00 yang terdiri dari kapal, mesin, alat tangkap, alat bantu penangkapan dan alat navigasi. Menurut Yanuartoro et al., (2013), harga setiap unit dari satu pemilik usaha penangkapan berbeda dengan pemilik usaha lainnya. Hal ini disebabkan oleh beberapa faktor, diantaranya tahun pembelian dikarenakan setiap unit usaha berbeda antara pemilik usaha penangkapan yang satu dengan yang lainnya, ada yang membeli barang bekas pakai dan ada juga yang mebeli barang baru yang tentunya lebih mahal harganya dari pada harga bekas pakainya. Selain itu, diketahui bahwa tiap tahun terjadi kenaikan harga dari masingmasing unit usaha penangkapan tersebut. Investasi yang terbesar dalam usaha penangkapan lift net adalah kapal. Biaya investasi yang terdapat pada usaha penangkapan began perahu (lift net) dapat dilihat pada Tabel 2 .

Tabel 2. Struktur biaya investasi yang dikeluarkan untuk usaha began perahu (lifnet)

\begin{tabular}{|c|c|c|c|c|c|}
\hline No & Nama Komponen & Jumlah & Satuan & Harga Satuan & Total Harga \\
\hline 1 & Body kapal & 1 & Unit & Rp 940.000.000 & Rp 940.000.000 \\
\hline 2 & Mesin induk & 2 & Unit & $\mathrm{Rp} 23.000 .000$ & Rp 46.000 .000 \\
\hline 3 & $\begin{array}{l}\text { Alat bantu } \\
\text { penangkapan }\end{array}$ & & & & \\
\hline & $>$ Lampu sorot & 112 & Buah & $\operatorname{Rp} 600.000$ & $\operatorname{Rp} 67.200 .000$ \\
\hline & $>$ Serok & 1 & Unit & $\mathrm{Rp} 300.000$ & $\mathrm{Rp} 300.000$ \\
\hline & $>$ Keranjang & 5 & Buah & Rp 130.000 & Rp 650.000 \\
\hline 4 & Alat tangkap & 1 & Unit & Rp 3.600 .000 & Rp 3.600 .000 \\
\hline 5 & Alat navigasi & & & & \\
\hline & $>$ GPS & 1 & Unit & $\operatorname{Rp} 4.500 .000$ & Rp 4.500.000 \\
\hline & $>$ Fish fender & 1 & Unit & $\operatorname{Rp} 3.500 .000$ & Rp 3.500 .000 \\
\hline & $>$ Kompas & 1 & Unit & $\mathrm{Rp} 1.500 .000$ & Rp 1.500 .000 \\
\hline & $>$ Radio SBB & 1 & Unit & $\mathrm{Rp} 4.300 .000$ & $\mathrm{Rp} 4.300 .000$ \\
\hline & & \multicolumn{3}{|c|}{ Jumlah Total } & Rp 1.071.550.000 \\
\hline
\end{tabular}

\section{Biaya Tetap}

Biaya tetap atau dalam istilah lain adalah fixed cost merupakan biaya yang tidak akan mengalami perubahan secara keseluruhan (total) walaupun terjadi peningkatan ataupun penurunan dalam suatu aktivitas bisnis (Winarko dan Astuti 2018). Biaya tetap yang dikeluarkan dalam usaha began perahu sebesar Rp. 144.825.000,00. Biaya tetap dalam usaha ini diantaranya adalah biaya penyusutan investasi, biaya perawatan (mesin, kapal, dan alat tangkap). Menurut Daryanto (2006), menyebutkan bahwa perawatan merupakan suatu usaha atau kegiatan yang penting untuk merawat suatu material agar material tersebut masih dapat dipakai secara produktif dan mempunyai umur yang lama. Berikut ini adalah rincian mengenai biaya tetap usaha began perahu (liftnet) tersaji pada Tabel 3. 
Tabel 3. Struktur fixed cost yang dikeluarkan usaha bagan perahu (liftnet)

\begin{tabular}{|c|c|c|c|c|c|}
\hline No & Biaya Tetap & Jumlah & Satuan & Harga Satuan & Total \\
\hline & Perawatan alat tangkap & 1 & tahun & 15.000 .000 & 15.000 .000 \\
\hline & Penyusutan & 1 & tahun & 108.825 .000 & 108.825 .000 \\
\hline & Perawatan kapal & 1 & tahun & 16.000 .000 & 16.000 .000 \\
\hline & Perawatan mesin & 1 & tahun & 5.000 .000 & 5.000 .000 \\
\hline & Total Biaya Tetap & & & & 144.825 .000 \\
\hline
\end{tabular}

\section{Biaya Variabel}

Biaya variabel merupakan biaya yang akan berubah jumlahnya sebanding dengan perubahan volume aktivitas usaha perikanan yang dilakukan (Oliii et al., 2021). Biaya variabel yang dikelurkan untuk usaha bagan perahu (liftnet) diantaranya adalah solar, oli, es, air minum dan bahan makanan (ransum). Jumlah total biaya variabel yang dikeluarkan dalam usaha bagan perahu (liftnet) selama 1 tahun kegiatan sebesar Rp. Rp 181.950.000. Berikut ini adalah struktur biaya varibel yang digunakan dalam usaha ini dapat dilihat pada Tabel 4.

Tabel 4. Struktur biaya variabel yang dikeluarkan usaha bagan perahu (liftnet)

\begin{tabular}{|c|c|c|c|c|c|}
\hline No & Jumlah Bahan & Jumlah & Satuan & $\begin{array}{l}\text { Harga } \\
\text { Satuan }\end{array}$ & $\begin{array}{l}\text { Jumlah } \\
\text { Harga }\end{array}$ \\
\hline 1 & Solar & 5.000 & Liter & Rp 9.500 & $\operatorname{Rp} 47.500 .000$ \\
\hline 2 & Oli & 5.000 & Liter & Rp 20.000 & Rp100.000.000 \\
\hline 3 & Es & 500 & Batang & Rp 19.000 & Rp9.500.000 \\
\hline 4 & Air gallon & 175 & Buah & $\mathrm{Rp} \quad 4.000$ & Rp700.000 \\
\hline \multirow[t]{6}{*}{5} & Bahan makanan & & & & \\
\hline & $>$ Beras & 50 & Karung & Rp 185.000 & Rp9.250.000 \\
\hline & $>$ Cabai & 150 & $\mathrm{Kg}$ & Rp 60.000 & Rp9.000.000 \\
\hline & $>\begin{array}{l}\text { Bawang } \\
\text { merah }\end{array}$ & 125 & $\mathrm{Kg}$ & Rp 15.000 & Rp1.875.000 \\
\hline & $>\begin{array}{l}\text { Bawang } \\
\text { putih }\end{array}$ & 75 & $\mathrm{Kg}$ & Rp 11.000 & Rp825.000 \\
\hline & $>$ Gula & 5 & Karung & Rp 660.000 & Rp3.300.000 \\
\hline
\end{tabular}

\section{Kelayakan Usaha}

Analisis kelayakan usaha alat tangkap bagan perahu (liftnet) di PPI Air Bangis ini digunakan untuk melihat ketercapaian tingkat keberhasilan usaha secara ekonomi. Analisis kelayakan usaha yang dilakukan dalam penelitian ini diantaranya penerimaan, keuntungan, dan tingkat keuntungan (R/C Ratio). Kesimpulan dari hasil analisis kelayakan usaha alat tangkap bagan perahu adalah layak untuk dijalankan dengan nilai penerimaan dalam 1 tahun sebesar $\mathrm{Rp}$. 442.500.000,00, dimana penerimaan hasil tangkapan meliputi musim puncak, musim sedang/biasa, dan musim paceklik. Keuntungan yang didapat dari usaha bagan perahu dalam 1 tahun usaha yaitu sebesar Rp. 115.725.000,00 dan nilai R/C ratio adalah 1,35 yang menyebutkan bahwa usaha tersebut layak dijalankan dan mendapatkan keuntungan. Berikut ini adalah rincian perhitungan Analisa usaha bagan perahu tersaji pada Tabel 5 . 
Tabel 5. Analisis kelayakan usaha alat tangkap bagan perahu (lifnet) di PPI Air Bangis

\begin{tabular}{|c|c|c|c|c|c|}
\hline No & $\begin{array}{c}\text { Musim } \\
\text { Penangkapan }\end{array}$ & Jenis Ikan & $\begin{array}{c}\text { Hasil } \\
\text { Tangkapan } \\
\text { (Kg) }\end{array}$ & $\begin{array}{c}\text { Harga } \\
\text { (Rp/kg) }\end{array}$ & $\begin{array}{c}\text { Penerimaan } \\
\quad(\mathbf{R p})\end{array}$ \\
\hline \multirow[t]{2}{*}{1} & Musim Puncak & Tongkol & 3.000 & $25.000,00$ & $75.000 .000,00$ \\
\hline & & Cumi-Cumi & 3.000 & $30.000,00$ & $90.000 .000,00$ \\
\hline \multirow[t]{3}{*}{2} & Musim Biasa & Tongkol & 2.500 & $30.000,00$ & $75.000 .000,00$ \\
\hline & & Cumi-Cumi & 2.500 & $35.000,00$ & $87.500 .000,00$ \\
\hline & Musim & & & & \\
\hline \multirow[t]{8}{*}{3} & Paceklik & Tongkol & 1.000 & $35.000,00$ & $35.000 .000,00$ \\
\hline & & Cumi-Cumi & 2.000 & $40.000,00$ & $80.000 .000,00$ \\
\hline & Total & & & & \\
\hline & Penerimaan & & 13.000 & & $442.500 .000,00$ \\
\hline & Biaya Tetap & & & & $144.825 .000,00$ \\
\hline & Biaya Variabel & & & & $181.950 .000,00$ \\
\hline & Keuntungan & & & & $115.725 .000,00$ \\
\hline & R/C Ratio & & & & 1,35 \\
\hline
\end{tabular}

Berdasarkan hasil perhitungan pada Tabel 5 menunjukkan bahwa penerimaan total hasil tangkapan selama 1 tahun usaha nelayan bagan perahu sebesar $13.000 \mathrm{~kg}$ (13 ton). Hasil tangkapan tersebut dipengaruhi oleh faktor musim, dimana pada musim puncak terjadi peningkatan hasil tangkapan dan musim paceklik mengalami penurunan hasil tangkapan. Menurut Dahen (2016) menyebutkan bahwa pendapatan akan tinggi apabila kemampuan produksi hasil tangkapan juga menghasilkan output yang tinggi juga.

Analisis kelayakan usaha lainnya yaitu dengan melihat nilai R/C Ratio. Analisis R/C rasio ini digunakan untuk mengetahui apakah usaha perikanan tangkap Bagan Perahu di PPI Air Bangis sudah efisien atau belum. Nilai R/C rasio ini didapat dari perbandingan antara penerimaan dan biaya. Hasil dari perhitungan bahwa nilai $\mathrm{R} / \mathrm{C}$ ratio usaha bahan perahu adalah 1,35 yang menyatakan bahwa usaha dikatakan layak dan menguntungkan. Menurut Mardianto et al., (2015) menyatakan bahwa nilai R/C ratio apabila lebih besar dari satu mengartikan bahwa usaha tersebut sudah menguntungkan dan layak untuk dijalankan.

\section{Kriteria Alat Tangkap Ramah Lingkungan}

Kriteria dari alat tangkap ikan ramah lingkungan menurut FAO (1995) dalam Salim et al., (2019) diantaranya adalah: mempunyai tingkat selektifitas tinggi, produkny tidak berbhaya bagi konsumen, tidak berbahaya untuk nelayan, tidak menangkap spesies yang terancam punah/dilindungi, tidak bersifat destruktif, ikan hasil tangkapan berkualitas, meminimalisir by-catch, dan meminimumkan dampak biodiversitas serta dapat diterima secara sosial. Analisis kriteria alat tangkap ramah lingkungan terhadap nelayan bagan perahu (lifnet) di PPI Air Bangis tersaji pada Tabel 6. 
Tabel 6. Analisis kriteria alat tangkap ramah lingkungan dari hasil wawancara dengan nelayan bagan perahu di PPI Air Bangis

\begin{tabular}{lllllllllll}
\multirow{2}{*}{ Kode Responden } & \multicolumn{1}{c}{ Kriteria Ramah Lingkungan } & \multirow{2}{*}{ Bobot } \\
\cline { 2 - 9 } & K1 & K2 & K3 & K4 & K5 & K6 & K7 & K8 & K9 & \\
\hline R-A & 3 & 4 & 4 & 3 & 4 & 2 & 4 & 4 & 2 & 30 \\
R-B & 3 & 4 & 4 & 3 & 4 & 3 & 4 & 4 & 3 & 32 \\
R-C & 3 & 4 & 4 & 3 & 4 & 2 & 3 & 4 & 4 & 31 \\
R-D & 3 & 4 & 4 & 2 & 4 & 3 & 4 & 4 & 4 & 32 \\
R-E & 3 & 4 & 4 & 3 & 4 & 3 & 4 & 4 & 3 & 32 \\
\hline
\end{tabular}

Rata-Rata Skoring 31,4

Keterangan:

K1 (selektivitas alat tangkap)

K2 (tidak merusak habitat)

K3 (tidak berbahaya bagi nelayan)

K4 (ikan berkualitas)

K5 (produk aman)

\author{
K6 (hasil tangkap sampingan) \\ K7 (dampak minim biodiversitas) \\ K8 (tidak membahayakan spesies dilindungi) \\ K9 (dapat diterima secara sosial)
}

Hasil wawancara dengan responden menyebutkan bahwa rata-rata nelayan mengungkapkan alat tangkap bagan perahu yang digunakan di PPI Air Bangis masuk dalam ketegori kriteria alat tangkap sangat ramah lingkungan dengan bobot 31,4. Hasil penilaian yang ditunjukkan pada Tabel 6 secara rinci menunjukkan bahwa dari semua responden (100\%) yang diwawancara menyatakan bahwa alat tangkap bagan perahu merupakan masuk dalam kriteria alat tangkap sangat ramah lingkungan dengan bobot berkisar 30 - 32 . Panduan pertanyaan yang diajukan kepada responden tentang kriteria alat tangkap ramah lingkungan ini berdasarkan code of conduct for responsible fishereis (CCRF) yang dicanangkan oleh FAO pada tahun 1995. Menurut Pramesthy et al., (2020), menyebutkan bahwa latar belakang dari pembentukan CCRF oleh FAO adalah perhatian dari dunia untuk menerapkan kode etik perikanan secara bertanggungjawab dalam konteks pemanfaatan sumberdaya perikanan secara berkelanjutan dan secara lestari.

$$
\text { Hasil wawancara juga }
$$

menyebutkan bahwa terdapat nilai maksimal (nilai 4) dari 4 kriteria alat tangkap ramah lingkungan untuk alat tangkap bagan perahu. Kriteria tersebut adalah tidak merusak habitat, tidak berbahaya bagi nelayan, produk yang dihasilkan aman bagi konsumen, dan tidak membahayan spesies yang dilindungi/terancam punah. Menurut Salim et al., (2019) menyebutkan bahwa penggunaan alat tangkap yang digunakan oleh nelayan ada beberapa tingkat bahaya tergantung pada jenis alat tangkap yang digunakan disertai dengan ketrampilan nelayan dalam menggunakan alat tangkap mengenai dampak alat tangkap tersebut. Prosedur penanganan ikan di atas kapal merupakan faktor yang paling utama dalam menentukan penanganan dan pengolahan ikan selanjutnya. Tekinik penanganan penangkapan ikan memiliki korelasi yang kuat terhadap kualitas hasil tangkapan

\section{KESIMPULAN DAN SARAN Kesimpulan}

Berdasarkan hasil penelitian dapat disimpulkan bahwa alat tangkap bagan perahu (liftnet) yang dioperasikan oleh nelayan di PPI Air Bangis secara ekonomi menguntungkan dan layak untuk dilanjutkan usahanya dilihat dari nilai $\mathrm{R} / \mathrm{C}$ rasio sebesar 1,35 dengan keuntungan per tahun sebesar Rp. 442.500.000,00. Dilihat dari segi lingkungan juga menunjukkan bahwa alat tangkap bagan perahu ini masuk dalam kategori sangat ramah lingkungan dari hasil penilaian kriteria 
alat tangkap ramah lingkugan berdasarkan konsep code of conduct for responsible fishereis (CCRF) menunjukkan bobot nilai rata-rata sebesar 31,4. Kelebihan dari penggunaan alat tangkap bagan perahu ini adalah tidak merusak habitat, tidak berbahaya bagi nelayan, produk yang dihasilkan aman untuk konsumen, serta tidak membahayakan spesies yang dilindungi. Hal ini dikarenakan operasi penangkapan bagan perahu ini dilakukan pada malam hari dan mudah terkontrol oleh nelayan terhadap hasil tangkapan sampingannya (by-catch).

\section{Saran}

Saran yang dapat diberikan dari penelitian adalah perlu adanya pengaturan zonasi dan daerah penangkapan bagan perahu yang dilakukan oleh nelayan di PPI Air Bangis, sehingga nantinya tidak terjadi penumpukan jika dilakukan pengembangan kegiatan perikanan tangkap untuk usaha bagan perahu. Hal ini sejalan dengan rencana strategis Menteri Kelautan dan Perikanan yang akan meningkatkan PNBP di sektor perikanan tangkap.

\section{UCAPAN TERIMA KASIH}

Pada kesempatan ini penulis mengucapkan terima kasih kepada pihakpihak yang telah membantu peneliti selama pengumpulan data, rekan-rekan tim peneliti dan beberapa Kelompok Nelayan di PPI Air Bangis yang telah memfasilitasi dan membantu kelancaran dalam kegiatan penelitian ini.

\section{DAFTAR PUSTAKA}

[BPS] Badan Pusat Statistik Nagari Air Bangis. (2019). Air Bangis Dalam Angka 2019. Kabupaten Pasaman Barat, Provinsi Sumatera Barat.

Arkham, M.N., Hutapea, R.Y.F., Tiku, M., Widayaka, R., \& Sari, E.M. (2020). Karakteristik FInansial Usaha Perikanan Pancing Ulur di Kawasan SAP Kepulauan Raja
Ampat dan Laut Sekitarnya. Jurnal Pengelolaan Perikanan Tropis, 4(2): 19-28.

Dahen, L.D. (2016). Analisis Pendapatan Nelayan Pemilik Payang di Kecamatan Koto Tangah Kota Padang. Journal of Economic and Economic Education. 5(1): 47-57

Daryanto. (2006). Dasar-Dasar Teknik Mobil. PT. Bumi Aksara. Jakarta.

Mardianto, Romadhon, M.M., \& Sukiyono, K. (2015). Struktur Biaya dan Efisiensi Usaha Perikanan Tangkap di Kota Bengkulu: Kasus pada Alat Tangkap Gillnet. Jurnal Bisnis Tani, 1(1): 1-10.

Oliii, M.Y.U.P., Buheli, S., \& Noor, S.Y. (2021). Analisis Ekonomi Bagan Perahu di Kecamatan Ponelo Kepulauan. Albacore, (5)1: 001006.

Pramesthy, T.D., Mardiah, R.S., \& Arkham, M.N. (2020). Modul Tata Laksana Perikanan Bertanggung Jawab (Code of Conduct for Responsible Fisheries: Edisi Pertama. Jakarta: Amafrad. 63p.

Putra, M.A.J., Bukhari, \& Lasibani, S. (2020). Kajian Pengaruh Waktu Hauling terhadap Hasil Tangkapan Bagan (Lift Net) di Air Bangis Kabupaten Pasaman Barat. Prosiding Hasil-Hasil Penelitian Mahasiswa, 19 (2): 13-18.

Salim, G., Firdaus, M., Alvian, M.F., Indrajo, A., Soejarwo, P.A., Daengs GS, A., \& Prakoso, L.Y. (2019). Analisis Sosial Ekonomi dan Keramahan Lingkungan Lat Tangkap Sero (Set Net) di Perairan Pulau Bangkudulis Kabupaten Tana Tidung, Kalimantan Utara. Buletin Ilmiah Marina (Sosek KP), 5(2): 8594. 
Setiawan, S., Junaidi, Efendi, Y. (2015).

Pola Pemasaran Ikan Olahan di

Nagari Air Bangis Kecanatan

Sungai Beremas Kabupaten

Pasaman Barat. Prosiding Hasil-

Hasil Penelitian Mahasiswa, 7 (2): 15-18.

Sugiyono. (2012). Metode Penelitian Kuantitatif Kualitatif dan RAT. Bandung: Alfabeta. 210 p.

Suman, A., Wudianto, Sumiono, B., Irianto, H.E., Bahrudin, \& Amri, K. (2014). Potensi dan Tingkat Pemanfaatan Sumberdaya Ikan di Wilayah Pengelolaan Perikanan Republik Indonesia (WPP RI). Jakarta: Ref Graphika. 224p.

Winarko, S.P., \& Astuti, P. (2018). Analisis Cost-Volume-Profit Sebagai Alat Bantu Perencanaan Laba (Multi Produk) pada Perusahaan Pia Latief Kediri. Jurnal Nusantara Aplikasi Manajemen Bisnis. 3(2): 9-21.

Yanuartoro, R., Ismail dan Sardiyatmo. 2013. Analisis Kelayakan Finansial Usaha Perikanan Tangkap Multigear di Desa Margorejo Kecamatan Cepiring Kabupaten Kendal. Journal of Fisheries Resources Utilization Management and Technology, 2(3):233-242. 